\title{
Relational attributes of political entrepreneurs: a network perspective
}

\author{
Dimitrios C. Christopoulos
}

\begin{abstract}
Political entrepreneurs are identified by personal characteristics similar to economic entrepreneurs, i.e. intellectual ability, good knowledge of their domain, team building skills, reputation, extensive networks, strategic vision and tenacity. Political entrepreneurs differ from economic agents by having a different incentive structure in attempting to control or exercise political power. A complete model of actor interaction would entail structural constraints and agency attributes coupled with an account of actor relational data. These we can best conceptualize as network data. Networks provide the context within which these actors thrive. Furthermore, as all entrepreneurial activity bears risks, networks are employed to mitigate them. Furthermore, accepting the premise that political entrepreneurs are network-dependent implies that their ability for political action is networkcontingent. Focusing on their network attributes, I attempt to identify those significant for the entrepreneurial behaviour of policy actors. A case study of agenda-setting among policy entrepreneurs provides the background for testing two alternative hypotheses on whether these actors exhibit incremental or opportunistic behaviour.
\end{abstract}

KEY WORDS interest intermediation; policy-making; political entrepreneurs; political networks. 